\title{
Building Rhizomatic Social Movements? Movement-Building Relays during the Current Epoch of Contention ${ }^{1}$
}

\author{
PETER NIKOLAUS FUNKE \\ University of South Florida, USA
}

\begin{abstract}
This article investigates the movement building dynamics of contemporary social movement milieus (such as particular protests, social forums or occupations). It develops the concept of the "relay" to introduce four ideal-type movement building relays understood as distinct movement milieus: clustering relay, networking relay, coalitioning relay, and organizing relay. Each ideal-type captures different points on a continuum of increasing movement building and thus for generating commonalities, shared understandings and identities, mobilizations and strategies. Focusing on what I call the current "rhizomatic movement epoch," which ranges from roughly the Zapatistas to the recent occupy-type protests, the relay framework can provide a larger conceptual umbrella or schemata for movement-to-movement transmissions. Moreover, focussing on "the situated" element of movements, the relay seeks to highlight the milieu of cooperation attempts, the physical, social and psychological space, the political-economic and socio-cultural setting, in which actors and groups interact. It focuses on those elements that are between the outside of the broader political economy and political opportunity structures (which arguably pre-structure the particular relay) and the "inside" of intra-group or movement behaviour (which in turn feeds back on the particular relay dynamics). While drawing on selected empirical examples from protests, social forums and other networking attempts, this article has a conceptual focus, exploring possibilities by adoption of such a relay lens to further our understanding of the achievements and challenges of current movement building dynamics and temporalities of social movements, the current movement milieu and social movement theory more generally. As such, my hope is to raise questions and open further research avenues of interest to social movement organizers and scholars.
\end{abstract}




\section{Introduction}

Examining the lack of viable opposition to the Bonapartist coup in France on 2 December 1851, Karl Marx (1978) argued that it was the lack of connections, "manifold relations" and absence of "political organization" (p. 124) that prevented the smallholding peasantry in $19^{\text {th }}$ century France to organize and mobilize as a class. Contrary to the Lassallean view of the inherent backwardness of the peasantry, Marx's argument in The Eighteenth Brumaire of Louis Bonaparte did not in fact dismiss the revolutionary capacity of the smallholding peasants but emphasized their lack of linkages and cooperation to realize it. As Marx (1856) stipulates in a letter to Engels, it was the isolation of the smallholding peasants which prevented them from representing and forging connections with towns and "possibilities of backing the proletarian revolution."

Manifold relations and political organizations are an arguably timeless concern for resilient movement building. As Tilly and Wood (2013) argue, (effective) activists and organizers for social change have always sought to generate sustained and organized efforts at collective claim making, organizing meetings, rallies and demonstrations, creating associations, coalitions and movements to further their cause. From workers', peasants' and civil rights' movements to today's "Arab Spring," broad mobilizations for emancipation thus require efforts at generating cooperation and linkages among activists and groups.

The arguably lasting and essential problematique of generating linkages and cooperation for sustained and resilient movement building describes a core concern for scholars and movement organizers. This "cooperation requirement" might have become even more urgent and complex in today's globalized world, where neoliberal capitalism is leading to more isolation, atomization and an apparent splintering of the working class (Lash \& Urry, 1987; Sites, 2007; Wacquant, 2010; Wolfson 2014), which is no longer confined to national borders (if it ever was) and composed "of more socially heterogeneous groups (including peasants, workers, indigenous people, middle-classes, scientists, etc.)" (Rucht, forthcoming).

This article investigates cooperation, linkages, and the movement-building dynamics of this "multitude" (Hardt \& Negri, 2004). Building on the work of scholars such as Fox (2004), Katsiaficas (2010), McAdam (1995), Meyer and Whittier (1994), Bandy and Smith (2004), and Tarrow (2011), who have investigated collaborations and connections, the following begins to develop the concept of the movement-building relay to gain analytic purchase on the workings and dynamics of linkages and cooperation of groups and activists. Starting from Ohlemacher's (1996) conception of a relay as "protest-proliferating contexts of networks [which] in the process of protest mobilization act as the fertile ground where seeds of protest can germinate and then [function] as a catalyst for mobilization efforts to flourish beyond the networks" (p. 201), the article introduces four ideal- typical conceptions of movement-building relays: clustering relay, networking 
relay, coalitioning relay, and organizing relay. Heuristically, each ideal-type captures different points on a continuum of increasing movement building and thus describes higher stages of commonalities, shared understandings and identities, mobilizations and strategies. While, clustering relays describe the lowest degree of convergence, shared identity and struggles, organizing relays conceptually characterize the highest level of confluence and shared strategy, political values, and identities.

While this article has a conceptual rather than an empirical focus, it provides stylized illustrations of the workings of such a relay lens from the ongoing arch of movement politics, protests and mobilizations. As I argue elsewhere in more detail (Funke, 2015), movement politics from at least the Zapatista uprising in Chiapas in the 1980s to the mass demonstrations against neoliberal globalization and war around the turn of the century to the most recent occupy-type protests and encampments can be understood as constituting a distinct and integrated arch of mobilizations - what McAdam \& Sewell have called "epochs of contention" (2001). Contrary to scholars who stress the differences between these protest cycles of, for example, the Global Justice Movement or Occupy Wall Street, I hold that while we can understand the Zapatistas or the more recent occupy-type protests as distinct protest cycles, they are nevertheless phenomena within or rather cycles that make up an integrated and identifiable movement epoch. The commonality of, for example the Zapatista or Occupy Wall Street, lies in their shared metalogic of movement politics. This logic informs the politics of each particular protest cycle - albeit in variegated and contextual ways - and constitutes the distinct and current epoch of contention.

Drawing on Deleuze and Guattari's (1980) concept of the rhizome, I argue that the current and ongoing epoch of contention ranging from at least the Zapatistas to the recent occupy-type protests, is informed by a shared "rhizomatic logic." Deleuze and Guattari develop the concept of the rhizome as an image of thought to describe an alternative way of conceptualizing the world. Unlike a tree structure, with only one path from one particular point to any other point, rhizomes represent non-hierarchical structures where any point can connect to any other point, generating links that can stretch, unevenly and asymmetrically, across spaces and times, scales, issues or strategies. As such, rhizomatic structures have "multiple entranceways and exits" (Deleuze \& Guattari, 1980, p. 21). Unlike a tree structure, with its "root node" or starting point and end-points or "leaf nodes," rhizomatic structures can be entered and exited from any point. Analogously, the currently dominant rhizomatic movement logic thrives on multiplicity and thus lacks a dominant core, center or axis. It enables the multi-connectivity and heterogeneity of current protest and mobilizing formations which lack a central actor, issue, strategy or ideology beyond opposition to neoliberalism and demands for "real" democracy. This rhizomatic logic is able to accommodate the considerable diversity and the multiplicity of struggles and possible futures, bringing about amorphous sets of associated and loosely linked organizations, groups and movements including anti-war, labour, 
environmental, feminist, peasant, indigenous and student groups from the political Left that oppose corporate globalization and neoliberal capitalism, imperialism and war (Conway, 2013).

On the basis of this shared rhizomatic movement logic, I suggest that the current "rhizomatic epoch of contention" is distinct from prior epochs of contention. Diverging from the so-called "old" movements of labour unions or political parties, which converged around the central class struggle of bourgeoisie and proletariat and different from the de-centering of that core struggle by the "new movement wave" of identity politics, civil rights, gender or environmental concerns, ${ }^{2}$ the dominant rhizomatic movement logic, on the other hand, seeks to bring together core characteristics of both the old and new movement Left. Current protests and mobilizations largely situate their resistance in the old movements' concerns with capitalist exploitation dynamics while accepting and embracing the heterogeneity of actors and struggles, internal networking logics and mobilization strategies characteristic of the new movements.

While autonomy and diversity are defining elements of the rhizomatic epoch of mobilizations, the multitude's congregating and networking at demonstrations, forums or occupy-type protests, however, suggest patterns of interactions and mechanisms for collaboration. To gain analytic purchase on these linkage and cooperation dynamics, this article develops the conceptual framework of the movement-building relay, briefly illustrating its dynamics and challenges with references from the ongoing rhizomatic epoch of contention.

\section{Linkages and Cooperation}

Scholars have investigated various dynamics of linkages among activists and forms of cooperation and transmissions between groups and movements. Drawing on Herbert Marcuse, George Katsiaficas (1989), for example, argues that mobilizations come about through what he calls the "eros effect." The concept of the eros effect refers to "the transcendental qualities of social movements, to what occurs in moments of suddenly popular social upheavals, which dramatically transforms established orders" (p. 1). Critically distinguished from earlier social movement theories such as crowd behaviour (Le Bon, 1895/1960), convergence theory (Cantril, 1941) or emergent norm theory (Turner \& Killian, 1987), Katsiaficas' (1989) concept of the eros effect seeks to "affirm the emotional content of social movements" (p. 3), referring to "the capacity of ordinary people, acting together, to profoundly change the basic facts of social life ... In moments of the eros effect, love ties exist between people that are some of the most exhilarating feelings imaginable [revealing] the aspirations and visions of the movement in their lived meaning" (2010, p. 242). The pioneering work of Katsiaficas has been furthered through the literature on passion and social movements (e.g. Goodwin, Japser, \& Poletta, 2001). 
Another prominent research focus has been on movement-to-movement transmissions, such as so-called "movement spillover" (Meyer \& Whittier, 1994), "movement spillout" (Hadden \& Tarrow, 2007), as well as the relationship between initiator movements and spin-off movements (McAdam, 1995). Meyer and Whittier conceptualize social movement spillover as explaining the ways that "ideas, tactics, style, participants and organizations of one movement often spill over its boundaries to affect other social movements" (1994, p. 290), whereas the notion of spin-off differentiates between two groups of movements. The first "initiator movement" sets off a particular protest cycle and inspires "spin-off” movements (McAdam, 1995). While changes in the political opportunity structures are identified as important explanatory factors (Tarrow, 2011), others focus on frame alignments, where particular constructions of meanings, issues, etc. become linked (Snow, Rochford, Wordern, \& Benford, 1986). In addition to movement spillover, Hadden and Tarrow have suggested that "social movement spillout" can be identified as a distinct dynamic. Movement spillout describes "the hollowingout of a social movement when its activists shift their activities to a cognate, but differently structured movement" (2007, p. 360, italics in original).

Based on these insights, this article develops the conceptual framework of the movement-building relay to provide a broader analytic or heuristic rubric to structure and conceive of movement emergence and development as the result of group, network or movement linkages and cooperation. ${ }^{3}$ The relay framework, I want to suggest, can provide a conceptual umbrella or larger schemata for the above-outlined perspectives on movementto-movement transmissions. While social movement research has often "resulted in a highly static view of collective action that privileges structures over process and single movements over cycles of protest" (McAdam, 1995, p. 218), the relay framework provides a more sequential, connected or capacious perspective, emphasizing the linkage and cooperation dynamics of multiple groups or networks. Rather than regarding the emergence or development of a particular social movement as a discrete event, the relay framework conceptualizes movement-building as the result of structured processes embedded in particular epochs of mobilizations and informed by distinct "mobilizing milieus" (such as particular protests, social forums or occupations, for example). As such, the relay framework also promises to be of analytic value when theorizing the temporality of social movements.

\section{Movement-Building Relays}

Generally speaking, a relay is an electrical switch that opens a higher-voltage circuit with a lower-voltage signal. Since relays control higher-voltage circuits with a lower-input signal, they can be regarded as a form of amplifier. With respect to radios, relays are used as a device that receives a signal from low-power or distant transmitter and retransmits it in order to increase the coverage area. Put differently, in the "radio-world," relays are devices that 
receive signals from lower-powered transmitters or from transmitters that are further away and pass the signal on in order to increase the area that the signal can travel.

Correspondingly, group and movement linkages and cooperation can be conceptualized as emerging through dynamics echoing relay processes. Activists, groups or networks, as well as particular protests, forums or occupations, can be thought of as operating as a sort of catalyst or amplifier for generating group connections, linkages or cooperation that could spread across space and time. Thus, relay dynamics can generate new networks and movements or "charge" pre-existing contacts in new ways and "spread the mobilization of networks outside themselves" (Ohlemacher, 1996, p. 201).

Furthermore, the concept of the movement-building relay shifts the analytic focus towards investigating the social movement environment or milieu. Generally speaking, the emphasis of much research has been on either the "outside" of movements, such as the political opportunity structures or on the "inside," including (often dyadic) interactions of groups and activists. Leaning on Staggenborg's (1998) conception of the "social movement community," which leads her to argue that "the culture of community of a protest cycle, rather than political opportunity, attracts many participants and provides organizational and tactical opportunities for new movements" (p. 180 ), the relay concept brings into focus the protest or movement-building milieu. Taking the Latin/French root of milieu as the "middle place," such a relay lens thus investigates the connecting area, the (infra)structure within which cooperation, such as protests, forums, occupations or longer-term convergence attempts including social or workers' centers' activities, can occur. The relay thus seeks to highlight the milieu of cooperation attempts, the physical, social and psychological space, the political-economic and socio-cultural setting, in which actors and groups interact. It focuses on those elements that are between the outside of the broader political economy and political opportunity structures (which arguably pre-structure the particular relay) and the "inside" of intra-group or -movement behaviour (which in turn feeds back on the particular relay dynamics).

To develop this relay framework for movement-building dynamics and dovetailing with recent work by Jeffrey Juris and his co-authors who have started to investigate ways of "thinking about movement building as an outcome of gatherings such as forums" (Juris et al., 2013, p. 3; italics in original), I focus here on what scholars have called "the situated" element of movements. The situated is a central space for generating linkages and cooperation. In addition to "the virtual" (electronic mailing lists, websites, etc.) and "the textual" (flyers, newsletters, etc.), the situated element of movements refers "to spaces and places of physical co-presence such as protests sites, encounters . . . social forums ... and festivals all of which involve considerable 'facework' - close interaction, trust building etc." (Chesters \& Welsh, 2011, p. 121). The situated as relay can thus be analyzed as receiving a host of weaker signals, bundling them and transmitting them across time and space. 
Moreover, "the situated" idea itself is being conveyed across space and time, taken up in other locations to then be enacted in context and locationspecific ways. For example, various Zapatista-inspired initiatives have been organized in places such as Los Angeles, adapting and altering Zapatismo tenets, reflecting the location and context specificity of Los Angeles (Zugman, 2008). Similarly the Indymedia movement has spread globally (Wolfson, 2014). Similarly, the social forum idea "traveled" the globe. Since the first World Social Forum in Porto Alegre, Brazil in 2001, countless regional, national or local social forums have been organized in ways that are reflective of the particular location and its dynamics. As Janet Conway writes,

Wherever the world event is organized, it enacts its own culturally-specific, geographically rooted social movement processes. . . Every edition of the World Social Forum is "placed" but transnational. The world-wide process is made up of myriad place-based processes, indisputably localized but both taken as a whole and in many of its constitutive parts, characterized by an expanding globality. $(2005)^{4}$

Most recently, the Occupy Wall Street idea traveled from Zuccotti Park in New York City to over 95 cities across 82 countries, ranging from Sydney to Frankfurt, from Los Angeles to Hong Kong, Rome, Mexico City and Tokyo, (Thompson, 2011) taking on location and context-specific characteristics while retaining occupy-type similarities or rather Wittgensteinian "family resemblances" (Occupy Wall Street Activists, 2011-2012).

While this article centers on the situated element, there is no reason to $a$ priori exclude the virtual or textual from the relay lens. Similarly, a more comprehensive analysis of the relay concept would of course also need to take the broader political economy as well as the political opportunity structures and intra- and inter-movement dynamics into account. For the purposes of this article, however, I am sidestepping these vital dimensions, which will be integrated in a subsequent article. The major aim in the following is to begin suggesting a particular way of conceptually thinking about and developing ideal-typical categorizations of diverse movement milieus as relays for distinct cooperation outcomes and thus broader movement-building dynamics.

Akin to relays in the field of electrical engineering, we can further distinguish between particular types of movement-building relays which enable distinct forms of cooperation. Bandy and Smith's (2004) edited volume provides a fruitful starting point for thinking about forms of cooperation and their enabling dynamics. The book investigates a range of transnational alliances and how they come about, examining "organizational mechanisms designed to encourage the formation of transnational solidarity" (p. 3). Bandy and Smith (2004) start off from Jonathan Fox's distinction between three forms of transnational cooperation: networks, coalitions, and movements (p. 476). ${ }^{5}$ Without claiming a necessary or wanted progression from one form of cooperation to the next, Bandy and Smith (2004) stipulate that "while networks have the lowest levels of formal organizational ties and integration, movements incorporate the most formal transnational structures. 
These greater levels of organizational integration signal higher levels of communication and action, allowing for possibilities for consensus building among participants in a movement's ideology and culture" (p. 3). As such, they suggest that networks describe generally informal ties and the dissemination of ideas follows unorganized or merely minimally structured paths. Coalitions describe cooperation patterns that tend to display the beginnings of more formal structures and routinized communication and resource flows. Finally, movements for Bandy and Smith (2004) are comprised of even more formally organized "Transnational Social Movement Organizations" (p. 4) which articulate decision-making procedures. The relay concept intervenes or seeks to further this line of research. It provides a framework which emphasizes or rather elaborates on the connecting links between a particular milieu, environment or (infra)structure as well as its respective dynamics and the realization (or not) of cooperation outcomes.

Based on these insights, with movement building relays as the connective tissue, the environment or (infra)structure within which various forms of cooperation (such as networks, coalitions, movement organizations) are generated can heuristically be separated into four ideal-types: Clustering relays describe the lowest degree of convergence(s), prioritizing the protection of the participants' autonomy while seeking to loosely connect them; Networking relays denote more pro-active milieus, encompassing dynamics that advance the institutionalization of more routinized linkages, shared actions and campaigns; Coalitioning relays are based on longerterm strategy and commitment to generating shared ideologies, values and political identities; Organizing relays represent milieus with the highest level of confluence, in which compromises and shared identity production become core concerns. Analytically linking these relay conceptions to cooperation outcomes would render the following heuristic schematic:

- clustering relays can generate networks

- networking relays can generate coalitions

- coalitioning relays can generate organizations

- organizing relays can generate antisystemic movements ${ }^{6}$

This simplified representation of relay dynamics and cooperation outcomes can be visualized as being different points on a continuum, describing increasing levels of shared identity and synergy creation and thus tighter movement-building dynamics. True to the definition of a continuum, which describes a succession or an aggregate, the four ideal-types are closely linked, overlapping and bleeding into each other and thus neatly distinguishable from each other merely for heuristic and analytic reasons. The following outlines the four suggested relay types and references stylized illustrations from the current rhizomatic epoch of mobilizations.

Clustering Relays

The dominant logic of clustering relays as movement-environments or 
-milieus for cooperation and linkages lies in safeguarding the autonomy of participants and groups and thus embracing diversity of tactics and struggles while still assembling them under a loosely defined umbrella. While participating groups and activists rarely share the same ideology, political culture or material interests (Fox, 2009), clustering relays enable the building of contacts and awareness of others' struggles and strategies and provide the environment to engage in joint actions with other groups and activists without foregoing one's own autonomy or having to compromise much of one's particular group identity. Clustering relays can enable loose coordination for short-term campaigns such as protest mobilizations, allowing groups and activists to agree on demonstrations and protest sites while accepting a host of different tactics and demands, thus acknowledging an equality and plurality of fronts of struggles. The outcomes are often more re-active and short-term activities such as "protest swarming," congregating on a given target and then quickly detaching again. The series of protests against neoliberal globalization such as the 1999 Seattle World Trade Organization protests can be conceptualized as having functioned as clustering relay, generating massive protests of a diversity of actors and groups, engaging in their autonomous yet linked protest forms.

The 2001 Genoa mobilizations against the Group of Eight Summit coordinated by the Genoa Social Forum (GSF) are illustrative of the functioning of a clustering relay milieu. The 300,000-strong Genoa protest was organized on the basis of the GSF framing document, which required all organizations and groups to accept and safeguard the diversity and autonomy of all participating groups. To accommodate this demand for autonomy, the roughly 700 participating groups ultimately agreed to demonstrate separately, albeit under one umbrella, against the Group of Eight Summit (Neale, 2002). The imperative of accepting the groups' autonomy and the unwillingness or inability to give up much of one's particular group identity and strategic outlook as well as the rejection of consolidating action and strategies towards any concrete overarching transformational project define clustering relay milieus. As the Genoa protests showed, the GSF as clustering relay enabled a multiplicity of groups and their various protest tactics to come together in a particular demonstration and to do so without subordinating their own tactics and demands to any other group or collective compromise.

However, this example of a clustering relay also illustrates shortcomings or challenges for resilient movement building. Prioritizing autonomy and diversity does not generate much more commonality beyond accepting differences. Accepting differences might function well as strategy for protests such as in Genoa, Seattle or elsewhere, where the target is given. It is, however, insufficient, I would argue, for more active movement building attempts, where targets are not given and participants seek to move beyond mere protest swarming activities and towards more pro-active movementbuilding work.

While clustering relays do not necessarily move beyond this stage of cooperation and linkages among the participants, they can generate networks, 
the lowest form of cooperation indentified by Fox and Bandy \& Smith. The series of protests against neoliberal globalization at the turn of the century could be conceptualized as having catalyzed the so-called anti-globalization movement or more precisely the alter-globalization networks. The alterglobalization networks propelled the World Social Forum and the global social forum process, an example of a networking relay.

\section{Networking Relays}

Networks can evolve into more regular and pro-active phenomena through movement-milieus, which I call networking relays. Networking relays denote processes, which maneuver activists and groups past the dynamics of clustering relays. Beyond fostering contacts and sharing information and experiences as well as joint actions based on loose and short-term coordination, networking relays generate dynamics that include the beginnings of processes that start advancing loosely institutionalized and longer-term linkages, joint actions and campaigns. While clustering relays function well to generate "swarming activities" such as protests, through networking relays cooperation is increasingly based on mutually-agreed-upon minimal goals beyond, for example, the identification of demonstration targets such as in Seattle or Genoa. Networking relays thus describe tendencies towards less re-active actions, often relying on constructing more intentional and pro-active spaces or strategies. While networking relays are characterized by a loose agreement on minimal goals and broad strategies, they do not necessarily rely on shared ideologies and political cultures or identities, still embracing a host of diverse actors, strategies, and fronts of struggle.

The World Social Forum and its global process provide insightful illustrations of networking relay dynamics. Taking place in the aftermath of the 1999 anti-World Trade Organization protest in Seattle, the first World Social Forum (WSF) in 2001 started out with the hope of moving beyond more re-active demonstrations and mass protests and, specifically, to move beyond "the failure of Seattle [which] was the inability to come up with a common agenda, a global alliance at the world level to fight against globalization (Klein, 2001)," as Christophe Aquiton of ATTAC who helped to organize the first WSF put it.

Since 2001, these unprecedented gatherings of social movements, networks, unions, non-governmental and other civil society organizations from the political Left have functioned as an incubator of, for instance, the massive globally coordinated anti-Iraq War protests on 15 February 2003, the abovereferenced anti-G8 demonstrations in Genoa, the European Marches against poverty, and, to a lesser degree, the electoral victories of social movementpowered governments in Latin America. Social forums have fuelled the antiausterity mobilizations in Europe, served as an important context for the revolution in Tunisia in 2010/11 and as nurturing and inspirational ground for the global justice networks writ large and the more recent occupy-type protests.

The WSF's networking relay milieu is based on the minimal goals enshrined 
in the Charter of Principles of the World Social Forum. ${ }^{7}$ The Charter stipulates a loosely enough defined common ground (such as opposition to neoliberalism and armed struggle as well as for participatory democracy) which is still able to assemble a multitude of actors with very variegated ideological outlooks, tactics and strategies. However, the social forum linkages are constructed with a view towards more structured or institutionalized and longer-term horizons. Networking relay dynamics can thus enable more sustainable convergences and cooperation among groups and activists beyond a "onetime" demonstration or campaign. The organization of the WSF itself provides an indication of how increased commonality is attempted. While this process has changed over time, since 2005 the program of the WSF has been entirely made up of self-organized and -governed activities proposed by the participating groups and movements themselves. On the basis of the proposed activities, the WSF organizing committee creates thematic terrains ${ }^{8}$ which are meant to be "the favoured context for expressing the plurality and diversity that are one of the main features and major strengths of the movement of resistance to neoliberal globalization. Nonetheless, any thematic fragmentation of discussions that may hamper or prevent achieving the above aims of convergence and synthesis is to be avoided." 9

Linking the networking relay dynamics to cooperation outcomes identified by Fox and Bandy and Smith (i.e. networks, coalitions, movement organizations), social forums have fostered, re-charged and furthered coalition building. While groups and networks such as the World March of Women or the peasant network Via Campesina have used the World Social Forum to further their respective groups' convergence(s) since the beginnings of the social forum process (Conway, 2013), it was, for example, the latest WSF in Tunis in 2013 which has since enabled the transnational network for communication rights and free media to consolidate their participants, groups, and networks and to build or re-charge coalitions, drawing in activists from the Maghreb region such as Reporters sans frontières (Tunisia), Radio Regueb (Tunisia) as well as media activists and journalists from Morocco, Algeria and Egypt, among others (Plöger, 2013). ${ }^{10}$

While social forums have been incubators and performed important networking relay functions, they have been less able than many had hoped to serve as vehicle for sustained organizing and durable movement building. As one activist put it, "A mobilization for a mass movement, which many have dreamed of, has not really happened" (cited in Bahn \& Haberland, 2003, p. 43). The emphasis on autonomy and diversity of actors, strategies and fronts of struggle still dominates networking relay milieus such as social forums. Networking relays display a wariness of institutions and organizational mechanisms that are geared towards working through differences and coming up with new synthesis, for which non-consensus-based decision-making, leadership development and a certain degree of hierarchy are necessary. To put it differently, networking relay milieus such as social forums and also occupy-type protests privilege networking over movement building. Subsequently, the result tends to lead to transient cooperation and coalition 
linkages rather than resilient and longer-term organizing. The occupy-type mobilizations are indicative of these dynamics. I would argue that, despite having mobilized very quickly and accelerated in 2011, they have not been able to organize in a sustainable and resilient way in spite of the ongoing presence of groups working under the label "occupy" such as Occupy Sandy, Occupy SEC or the related European Blockuyp actions against the European Central Bank in Frankfurt, Germany. The reasons, as I shall suggest below, also have to be seen in the particular rhizomatic logic undergirding the current epoch of contention or mobilizations and thus movement or activist politics today, which make "higher levels" of movement-building challenging.

\section{Coalitioning Relays}

Conceptually speaking, networking relay milieus and resulting coalitions can propel cooperation towards the next stage of movement building, by functioning as coalitioning relays. Coalitioning relays encompass the characteristics of the former two phases but further deepen and institutionalize cooperation, generating increasing synergies and commonality. Coalitioning relays are arguably based on even more long-term strategy and tend to rely on more commitment to developing shared ideologies, values and political identities for movement building. Coalitioning relays thus refer to movementbuilding processes that further the compression and coagulation of group or movement intersections, seeking more resilient formations and more unitary fronts. They encompass more explicit visions of aspired movement outcomes, more direct and focused interactions, and a more articulated and sharpened common identity. Coalitioning relays provide the possibilities for sustained organizing of constituencies and warrant agreeing upon decisionmaking procedures and leadership development aspects. Compromises and shared identity production become core concerns within coalitioning relay milieus for which mechanisms have to be devised that approach difference not as absolutes but rather as something to transcend and through which to arrive at a new synthesis (Nunes, 2006). This does not necessarily mean that difference and autonomy are sacrificed but it does suggest that they are less dominating concerns.

In Fox and Bandy and Smith's categorization, coalitioning relays can generate (transnational) movement organizations which they describe as "more formal structures to help routinize communications and resource flows as well as to articulate procedures for making decisions that affect the alliance" (Bandy \& Smith, p. 4). With the important exception of the Zapatista and more local initiatives such as the Media Mobilizing Project ${ }^{11}$ (Funke \& Wolfson, 2013) that have been able to generate organizing relay milieus for their distinct and bounded spheres, the broader alter-globalization networks, the social forum process or occupy-type mobilizations have arguably not been able to generate successful organizing relay milieus for movement building despite various attempts.

Two unsuccessful attempts aimed at more unifying projects with the potential to generate movement organizations came out of the broader WSF 
orbit: the "Porto Alegre Manifesto" in 2005 and the "Bamako Appeal" a year later. ${ }^{12}$ Both "appeals" expressed the wish of some to move the WSF away from being merely an "open-space," or in this article's framework a networking relay, and more toward being a political actor, proposing potential converging topics and working on shared strategies. Within a relay perspective, the attempt was to generate organizing relays and to further movement-building dynamics and organizations.

While it is beyond the scope of this article to analyze the host of reasons that help explain the lack of resonance of these initiatives, I suggest, as referenced earlier, that the dominant rhizomatic movement logic is challenging for more concentrated movement building. Safeguarding diversity and autonomy, multiplicity of struggles, strategies and possible futures, and preserving horizontalism, which is arguably at the core of the dominant rhizomatic logic, are high hurdles for such initiatives and more long-term movement-building strategies. The latter requires the willingness to transcend the acceptance of "diversity for diversity sake" and to generate more coherent fronts of struggle and movement capacity beyond mere networking. Such convergence processes would, however, challenge core tenets of the dominant rhizomatic movement logic and thus would likely sow derision among today's diverse and autonomous groups and movements.

Nevertheless, a still on-going attempt to generate coalitioning relay environments that can foster more unitary fronts and further movement coagulation and intersections can be seen in developments within the United States Social Forum (USSF). USSF organizers emphasize more than other forums the need to move towards "establishing a space with a particular racial and class composition, balance of power, and movement building strategy" (Juris, 2008, p. 364). What Jeffrey Juris calls the creation of "intentional spaces" illustrates for our purposes here potential transitions from networking relay milieus to coalitioning relay environments, as the USSF space is intentionally designed to allow for the construction of spaces that foster movement-building capacities and thus (movement) organizations as cooperation or relay outcomes. With respect to the USSF, this intentionality strategy was also devised to overcome the glaring whiteness and middle class nature of forums and to thus empower the voices from lower-class constituencies and more racially diverse participants. While this might appear as merely accommodating more diversity, the conscious encouragement of more diversity was in fact geared towards generating more wilful connections and thus furthering a more focused movement-building approach. Beyond overcoming the middle-class bias, the intended inclusion of lower classes and racially diverse constituencies is also necessary as effective and resilient movement building needs to be grounded in communities and led by those most disaffected by neoliberal capitalism.

\section{Organizing Relays}

The final stage in this stylized and ideal-type continuum of movementbuilding relays could be thought of as organizing relays, which would describe 
movement milieus and (infra)structures that lead movement organizations (as outcomes of coalitioning relays) to paraphrasing Marx's famous dictum, to begin transforming a movement "in itself" towards a movement "for itself."

Organizing relays would thus further increase the dynamics of compressing and converging of actors, strategies, and struggles. Compromises and shared identity production become core concerns for which mechanisms of organizing and decision-making are needed to generate sustainable commonalities or agreements and thus movement-building capacity that can lead towards generating antisystemic movements (Arrighi, Hopkins \& Wallerstein, 1989). Core organizers of the 2007 anti-Group of Eight protests in Heiligendamm (Germany) put it succinctly, stating that now needed is not "different political currents engaging in different forms of action-in a spirit of solidarity but without jeopardizing their own identities [but] in the direction of a 'becoming-other, together.' This meant collectively devising and carrying out forms of action new to all, actions and alliances that took people beyond their comfort zones towards the practical constitution of new commons, and therefore new common potentials" (Move into the light, 2007, p. 4).

In sum, organizing relay dynamics arguably transcend core characteristics of the rhizomatic logic. They move away from privileging grassroots democracy and prefigurative politics and a politics of horizontality and decentralization gives way to more structured networks with hierarchical elements and decision-making processes as well as leadership development. Moreover, it entails building a shared identity, which ultimately asks participating groups to generate new and shared connections and convergences beyond their particular struggle.

\section{Concluding Remarks}

This article is a first attempt to provide a framework of how to conceptualize various movement-building milieus. Using the metaphor of the relay and conceptualizing it as a continuum, this article sketched four ideal-types: clustering, networking, coalitioning, and organizing relays as related yet heuristically distinct types of movement-building milieus. While this framework is of course a stylized schemata, the relay rubric is nevertheless helpful, I believe, in beginning a process of identifying and examining particular and varying movement-building dynamics and cooperation outcomes by focusing on the milieu, the (infra)structure or environment in which groups and activists engage and seek linkages and cooperation. As a continuum, clustering relays describe processes which allow for the first beginnings of shared movement practices and commonalities, potentially leading to network forms of cooperation. Networks could then catalyze networking relays, which can be thought of as beginning to build movement coalitions, condensing and converging around overlapping dimensions or transversal axes and building more intentional processes of generating 
commonalities for strategizing and organizing, employable across a host of situations and particular struggles. Put differently, networking relays enable the beginnings of transcending particularisms and generating novel synergies and shared identities, possibly ushering in movement coalitions. Coalitioning relays are subsequently geared towards fostering a more pointed front of struggle in order to further developments towards shared and more strongly institutionalized movement organizations. Finally, we can conceptualize an organizing relay milieu or (infra)structure which is conducive to enabling developments, which can lead towards the construction of broader and resillient antisystemic movements.

This article also suggests that the dominant rhizomatic movement logic impacts cooperation potentials in general and relay milieus in particular. Embracing autonomy and the diversity of actors, strategies and fronts of struggles, this logic is well geared to amplifying lower cooperation dynamics such as clustering- and networking-relay milieus. Hence, this rhizomatic logic helps explain the surprising "degree to which the global left has not fractured into its historical constituent parts of liberalism, Marxism, and anarchism-autonomism" (Reitan, 2011, p. 52, italics in original). It has thus arguably allowed for a stunning coming together of groups and movements, having "relayed" and facilitated mobilizations and forged new constellations by linking various groups and movements across space and diverse issue areas (Olesen, 2011).

While the rhizomatic texture thus arguably allows for unprecedented ties as well as the tempering and managing of the movement epoch's inherent antinomies, its logic simultaneously limits the degree of congealed and resilient movement building in general and the construction of coalitioningor organizing-relay milieus in particular. Integral characteristics of the rhizome foster a rather thin articulation of commonalities and convergences, which results in a politics that is often unable to move beyond mere symbolic acts, re-active resistances and loose networking rather than towards a politics of organizing for concrete and long-term movement building.

The rhizomatic logic is thus a double-edged sword, operating well as clustering and networking relay, generating awareness, contacts, and linkages of the various struggles without encroaching on the independence of groups and movements. Yet, this rhizomatic logic that promotes and protects diversity is at the same time less able to function as a coalitioning or organizing relay for movement building that can credibly aim at meaningful changes in social structures. The latter, I suggest, would arguably require more transversal mechanisms and structures that could generate new syntheses across movements and groups, but this is simultaneously a project that would likely provoke resistance from among today's diverse and autonomous groups.

While this article was only able to briefly sketch empirical illustrations of the relay continuum, a next step would be to investigate further movementbuilding examples to ascertain the usefulness of such a relay lens. More empirical cases would also allow us to make more concrete the conceptual differences between the four ideal relay types outlined above. Moreover, 
expanding the empirical data would arguably lead to an expansion or increased differentiation of the relay continuum.

An additional research avenue dovetailing with the arguments in this article would be to investigate the relationship between relays and the conceptions of protest cycles, which Tarrow defines as a "phase of heightened conflict across the social system with intensified interactions between challengers and authorities, which can end in reform, repression and sometimes revolution" (Tarrow, 2011, p. 153). In what way, for instance, might networking and coalitioning relays be seen as attempts to break the cyclical rise and fall of protest and social movement activities? How successful (or not) are they, respectively? Finally, I hope this article also might be of interest to activists and organizers in more directly thinking about or rather having the beginnings of some categories with which to conceptualize their own work and to further successful and resilient movement-building strategies.

\section{Notes}

1 I would like to thank the anonymous reviewers for invaluable feedback and suggestions as well as Tanya Basok, Nicole Noel and the copyeditor for their editorial guidance and very helpful substantive advice.

2 While recognizing the problematic nature of periodization (Calhoun, 1993) since they neglect continuities and hide dissonance within specific moments, thinking in periods as Jameson suggests (1990) allows us to see patterns where we would otherwise merely see a cacophony of phenomena.

3 For a related an account stressing organizational density as vital element of protest cycles see Minkoff (1997).

4 See also: Janet Conway (2008).

5 The focus of their edited volume is on transnational cooperation but these three forms are not a priori limited to the transnational sphere.

On antisystemic movements see Arrighi, Hopkins, Wallerstein (1989).

http://www.forumsocialmundial.org.br/main.php?id_menu=4\&cd_language $=2$

Such as "Asserting and Defending the common properties of Land and the Peoples", "Art and Creation: building the cultures of resistance of the peoples", "Sovereign Economies by and for the peoples: against neoliberal capitalism", "Social Fights and democratic alternatives: Against neoliberal domination", "Peace and Demilitarization: Fight against war, free commerce and the debt".

9 http://www.forumsocialmundial.org.br/dinamic.php?pagina=eixo_transv_2005_ing

10 On Media and social movement networks see Wolfson (2013 \& 2014).

11 The Media Mobilizing Project (MMP) is a network of organizations across the Philadelphia metro-region. Established in 2005, MMP aims to "build a movement to end poverty led by the poor and working class, united across color lines." MMP engages in long-term movement building, seeking to foster tight connections between its constitutive groups, which range from high school students, to janitors, cab drivers, nurses and security guards (see: http://www.mediamobilizing.org/).

12 For a discussion of the Appeal of Bamako see for instance: Sen \& Kumar (2007).

\section{References}

Arrighi, G., Hopkins, T. K. \& Wallerstein, I. (1989). Antisystemic Movements. New York: Verso. Bahn, E., \& Haberland, M. (2003). Projektbericht: Initiative für ein Berliner Sozial Forum, Projektkurs Soziale Bewegungen und außerinstitutionelle Initiativen in Berlin, Freie 
Universität Berlin, (Otto Suhr Institut, Sommersemester).

Bandy, J., \& Smith, J. (Eds.). (2004). Coalitions across borders: Transnational protest and the neoliberal order. Lanham, MD: Rowman \& Littlefield Publishers.

Calhoun, C. (1993). New social movements of the early nineteenth century, Social Science History, 17(3), 385-427.

Cantril, H. (1941). The psychology of social movements. New York: John Wiley and Sons.

Chesters, G., \& Welsh, I. (2011). Social movements: The key concepts. London and New York: Routledge.

Conway, J. M. (2005, February). The empire, the movement, and the politics of scale: Considering the World Social Forum. Paper presented at Towards a Political Economy of Scale: Studies in the Political Economy Conference, York University, Canada.

Conway, J. M. (2008). Reading Nairobi: Place, space, and difference at the 2007 World Social Forum," Societies Without Borders 3, 1, 2008, pp. 48-71.

Conway, J. M. (2013). Edges of global justice: The World Social Forum and its "others." London and New York: Routledge.

Deleuze, G., \& Guattari, F. (1980). A thousand plateaus: Capitalism and schizophrenia. Paris: Minuit.

Fox, J. (2004). Assessing binational civil society coalitions: Lessons from the Mexico-U.S. experience. In K. J. Middlebrook (Ed.), Dilemmas of change in Mexico (pp. 466-522). London: Institute for Latin American Studies, University of London.

Fox, J. (2009). Coalitions and networks. In H. Anheiner \& S. Toepler (Eds.), International encyclopedia of civil society (pp. 486-492). New York: Springer Publication.

Funke, P., \& Wolfson, T. (2013) Communication, class and concentric media practices: Developing a contemporary rubric. New Media \& Society, published online before print April 9, 2013

Funke, P. (2015) The Rhizomatic Logic: The Contemporary Wave of Social Movement Politics from the Zapatista to the Arab Spring \& Occupy (manuscript to be submitted for publication in 2014).

Goodwin, J. Japser, J. M., \& Poletta, F. (Eds.). (2001). Passionate politics: Emotions and social movements. Chicago, IL: University of Chicago Press.

Hadden, J., \& Tarrow, S. (2007). "Spillover or spillout? The global justice movement in the United States after 9/11," Mobilizations: An International Quarterly, 12(4), 359-376.

Hardt, M., \& Negri, A., (2004). Multitude: War and democracy in the age of empire. New York, NY: The Penguin Press, 2004.

Jameson, F. (1990). Postmodernism, or, the cultural logic of late capitalism. Durham, NC: Duke University Press.

Juris, J. S. (2008). Space of intentionality: Race, class, and horizontality at the United States social forum, Mobilizations: An International Quarterly, 13(4), 353-372.

Juris, J. S., Bushell, E. G., Doran, M., Judge, J. M., Lubitow, A., Maccormack, B., \& Prener, C., (2013). Movement building and the United States Social Forum, Social Movement Studies.

Katsiaficas, G. N. (1989). The eros effect. Paper presented at the American Sociological Association Annual Meeting, San Francisco.

Katsiaficas, G. N. (2010). Between ballots and bullets. In B. Davis, W. Mausbach, \& M. Klimke (Eds.), Changing the world, changing oneself: Political protest and collective identities in West Germany and the U.S. in the 1960s and 1970s. New York: Berghahn Books.

Klein, N, (2001, March 1) A fete for the end of the end of history. The Nation. Retrieved from http://www.thenation.com/doc/20010319/klein/single

Lash, S., \& Urry, J. (1987). The end of organized capitalism. Madison, WI: University of Wisconsin Press.

Le Bon, G. (1960). The crowd. New York, NY: Viking Press (Original work published 1895).

McAdam, D. (1995). "Initiator" and "spin-off" movements: Diffusion processes in protest cycles. In M. Traugott (Ed.), Repertoires and cycles of collective action (pp. 217-239). Durham, NC: Duke University Press.

McAdam, D., \& Sewell, W. H. (2001). It's About Time: Temporality in the Study of Social Movements and Revolutions. In R. R. Aminzade, J. A. Goldstone, D. McAdam, E. J. Perry, W. H. Sewell, S. Tarrow \& C. Tilly (Eds.), Silence and Voice in the Study of Contentious Politics (pp. 89-125). Cambridge: Cambridge University Press.

Marx, K. (1856). Letter to Engels, 16 April 1856, Retrieved from https://www.marxists.org/ 
archive/marx/works/1856/letters/56_04_16.htm

Marx, K. (1978). The eighteenth Brumaire of Louis Bonaparte. In R. C. Tucker (Ed.), The Marx Engels Reader (pp. 594-617). New York, NY: W.W. Norton Company.

Meyer, D., \& Whittier, N. (1994). Social movement spillover, Social Problems, 41(2), 277-298.

Minkoff, D. C. (1997, October). The sequencing of social Movements, American Sociological Review, 62(5), 779-799.

Move into the light. (2007, December). Move into the light. Postscript to a turbulent 2007. In Turbulence: Ideas for movement. Retrieved from http://turbulence.org.uk/turbulence-3/ move-into-the-light/introduction

Neale, J. (2002). You are G8, We are 6 Billion: The Truth Behind the Genoa Protests. London: Vision.

Nunes, R. (2006). Nothing is what democracy looks like: Openness, horizontality and the movements of movements. In D. Harvie, K. Milburn, B. Trott, D. Watts (Eds.), Shut them Down! The Global G8, Gleneagles 2005 and the Movement of Movements, (pp. 299-319). Automedia.

Occupy Wall Street Activists, (2011-2012). Occupy Wall Street revolution handbook, The unauthorized Collector's Edition. Fix Bay Inc Publishing.

Ohlemacher, T. (1996). Bridging people and protest: Social relays of protest groups against lowflying military jets in West Germany, Social Problems, 43(2), 197-218.

Olesen, T. (Ed.). (2011). Power and Transnational Activism. London and New York: Routledge.

Plöger,A.(2013,April 12), REPORT: Das Netzwerk freierMedien audn fürKommunikationsrechte im WSF Prozess, Rosa Luxemburg Stiftung, Berlin.

Reitan, R. (2011). Coordinated power in contemporary leftist activism. In T. Olesen (Ed.), Power and transnational activism (pp. 51-72). London and New York: Routledge.

Rucht, D. (forthcoming). Social fora as public stage and infrastructure of global justice. In S. Seferiades (Ed.), Collective action and social movements in the $21^{\text {st }}$ century. Athens, Greece: Themelio.

Sen, J., \& Kumar, M. (Eds.). (2007). A political programme for the world social forum? Democracy, substance and debate in the Bamako appeal and the global justice movements. New Dehli: CACIM and Durban: Center for Civil Society.

Sites, W. (2007). Contesting the neoliberal city? Theories of neoliberalism and urban strategies of contention. In H. Leitner, J. Peck, \& E. S. Shepperd (Eds.), Contesting Neoliberalism: Urban Frontiers (pp. 116-138). New York, NY: The Guilford Press.

Snow, D. A., Rochford, E. B. Jr., Worden, S. K., \& Benford, R. D. (1986). Frame alignment processes, micromobilization, and movement participation. American Sociological Review, 51(4), 464-481.

Staggenborg, S. (1998). Social movement communities and cycles of protest: The emergence and maintenance of a local women's movement, Social Problems, 45(2), pp. 180-204.

Tarrow, S. (2011). Power in movement: Social movements and contentious politics ( $3^{\text {rd }}$ ed.) Cambridge: Cambridge University Press.

Thompson, D. (2011, October 15). Occupy the world: The "99 percent" movement goes global, The Atlantic. Retrieved from http://www.theatlantic.com/

Tilly, C., \& Wood, L. J. (2013) Social movements, 1768-2001 (3 $3^{\text {rd }}$ ed.). Boulder, CO: Paradigm Publisher.

Turner, R. H., \& Killian, L. M. (1987). Collective behavior. Englewood Cliffs, NJ: Prentice Hall.

Wacquant, L. (2010). Crafting the neoliberal state: Workfare, prisonfare and social insecurity, Sociological Forum, 25(2), 197-220.

Wolfson, T. (2013). Democracy or autonomy? Indymedia and the contradictions of global social movement networks, Global Networks 13, 3, 2013, pp. 410-424.

Wolfson, T. (2014). Digital Rebellion: The Birth of the Cyber Left. Champaign: University of Illinois Press.

Zugman, K. (2008, September). The "other campaign:" The EZLN and new forms of politics in Mexico and the United States, New Political Science: A Journal of Politics and Culture, 20(3), 347-367. 